\title{
In Situ Investigation of the Evolution of Lattice Strain and Stresses in Austenite and Martensite During Quenching and Tempering of Steel
}

Villa, M.; Niessen, F.; Somers, M. A. J.

Published in:

Metallurgical and Materials Transactions A: Physical Metallurgy and Materials Science

Link to article, DOI:

10.1007/s11661-017-4387-0

Publication date:

2018

Document Version

Peer reviewed version

Link back to DTU Orbit

Citation (APA):

Villa, M., Niessen, F., \& Somers, M. A. J. (2018). In Situ Investigation of the Evolution of Lattice Strain and Stresses in Austenite and Martensite During Quenching and Tempering of Steel. Metallurgical and Materials Transactions A: Physical Metallurgy and Materials Science, 49(1), 28-40. https://doi.org/10.1007/s11661-0174387-0

\section{General rights}

Copyright and moral rights for the publications made accessible in the public portal are retained by the authors and/or other copyright owners and it is a condition of accessing publications that users recognise and abide by the legal requirements associated with these rights.

- Users may download and print one copy of any publication from the public portal for the purpose of private study or research.

- You may not further distribute the material or use it for any profit-making activity or commercial gain

- You may freely distribute the URL identifying the publication in the public portal 
1 In situ investigation of the evolution of lattice strain and stresses in austenite and martensite during quenching and tempering of steel

\author{
M. Villa ${ }^{1, \mathrm{a}}$, F. Niessen ${ }^{2, \mathrm{~b}}$, M.A.J. Somers ${ }^{1, \mathrm{c}}$ \\ ${ }^{1}$ Technical University of Denmark, Department of Mechanical Engineering, 2800 Kgs. Lyngby, Denmark \\ ${ }^{2}$ Technical University of Denmark, Danish Hydrocarbon Research and Technology Centre, 2800 Kgs. Lyngby, \\ Denmark \\ amatv@mek.dtu.dk; ${ }^{\text {b }}$ frannie@dtu.dk; $;{ }^{\text {somers@mek.dtu.dk }}$
}

\title{
$9 \quad$ Abstract
}

10 Energy dispersive synchrotron X-ray diffraction was applied to investigate in situ the evolution of

11 lattice strains and stresses in austenite and martensite during quenching and tempering of a soft

12 martensitic stainless steel. In one experiment, lattice strains in austenite and martensite were

13 measured in situ in the direction perpendicular to the sample surface during an austenitization,

14 quenching and tempering cycle. In a second experiment, the $\sin ^{2} \psi$ method was applied in situ

15 during the austenite-to-martensite transformation to distinguish between macro- and phase specific

16 micro-stresses and to follow the evolution of these stresses during transformation. Martensite

17 formation evokes compressive stress in austenite that is balanced by tensile stress in martensite.

18 Tempering to $748 \mathrm{~K}\left(475^{\circ} \mathrm{C}\right)$ leads to partial relaxation of these stresses. Additionally, data reveals

19 that (elastic) lattice strain in austenite is not hydrostatic but $h k l$ dependent, which is ascribed to

20 plastic deformation of this phase during martensite formation and is considered responsible for 21 anomalous behavior of the $200_{\gamma}$ reflection.

Keywords: Martensite; Synchrotron X-ray diffraction (XRD); Residual stresses; Tempering; Steel 
26 Modern steels are multi-phase materials. The response of a multi-phase material to an applied load is a function of the volume fraction, distribution, orientation and shape of the phases present $[1,2]$, as well as of the presence and magnitude of internal stresses, which remain after processing [3]. On loading, the applied external forces are superimposed on the internal stresses $[1,2]$. Internal stresses can be classified by the length scale over which they equilibrate $[1,4,5]$. Macrostresses (type I) act over large distances and are an average over all phases and grains present; micro-stresses vary from grain to grain and from phase to phase (type II) or within a single grain/phase (type III). Internal stress can arise as a consequence of inhomogeneous elastic and thermal properties [2,3], inhomogeneous plastic strain [2], or a phase transition occurring in association with a shape change [5].

The austenite $(\gamma)$-to-martensite $\left(\alpha^{\prime}\right)$ transformation in steel is associated with a shape change, the so called transformation strain, which consists of a volume expansion of approx. 3\% and a shear [6-9]. Additionally, austenite and martensite have different thermal and elastic properties. Thus, martensite formation is associated with the development of residual stress in the material, with contributions from the transformation itself as well as thermal mismatch $[3,9]$.

The development of macro-stresses during quenching of steel parts is a well described subject [3$5,9,10]$. Similarly, the generation of lattice defects (micro-stresses of type III) in austenite during martensite formation has been investigated in details [6-8]. On the other hand, the evolution of micro-stresses of type II is controversial: martensite formation has been reported to invoke compressive stress [11-22], tensile stress [22,23], or no stress [24-27] in austenite, while information about the stress state in the developing martensite is incomplete. The evolution of micro-stresses of type II during martensite formation is of fundamental interest because these stresses affect the transformation kinetics [28]. In the absence of macro-stresses (type I), the grain- or phase-specific micro-stresses (type II) can be evaluated from the lattice strain as experimentally determined by X-ray diffraction (XRD) [1,4] by measuring in the direction $i$ the lattice spacing, $d_{i}^{h k l_{\varphi}}$, for a given family of lattice planes, $\{h k l\}$, in the crystalline phase $\varphi$. Comparison of the measured lattice spacing with a reference lattice spacing, $53 d_{r e f}^{h k l_{\varphi}}$, provides the lattice strain, $\varepsilon_{i}^{h k l_{\varphi}}$ :

$54 \varepsilon_{i}^{h k l_{\varphi}}=\frac{d_{i}^{h k l_{\varphi}}-d_{r e f}^{h k l_{\varphi}}}{d_{r e f}^{h k l_{\varphi}}}$ 
55 The $h k l$-specific strain $\varepsilon_{i}^{h k l_{\varphi}}$ represents the average lattice strain, $\left\langle\varepsilon^{h k l} \varphi\right\rangle$, for a given

56 family of lattice planes $\{h k l\}$ in the probed volume and can be converted into an average

57 (hydrostatic) stress, $\left\langle\sigma^{\varphi}\right\rangle$, applying the appropriate X-ray elastic constants, XECs [4]:

$\left\langle\varepsilon^{h k l_{\varphi}}\right\rangle=\left(3 \cdot S_{1}^{h k l_{\varphi}}+\frac{1}{2} S_{2}^{h k l_{\varphi}}\right) \cdot\left\langle\sigma^{\varphi}\right\rangle$

59 where $S_{1}^{h k l_{\varphi}}$ and $\frac{1}{2} S_{2}^{h k l_{\varphi}}$ are the XECs of phase $\varphi$ for probing the family of lattice planes $\{h k l\}$.

60 Experimental XRD work on the evolution of lattice strain and phase-specific stresses in steel during 61 martensite formation was firstly reported in 1957 [11]. It was suggested that a low content of retained austenite is in a state of compressive stress. In the same year, comparison of the lattice parameter of $\mathrm{Fe}-30 \% \mathrm{Ni}$ austenite in as-received condition and after approx. $80 \%$ transformation by sub-zero Celsius treatment did not show a significant change [24]. Therefore, it was concluded that martensite formation did not evoke micro-stresses of type II in austenite.

More than 10 years later [12], Ridley et al. reproduced the results in Ref. [11] and suggested that data could be interpreted in terms of a state of compression in austenite caused by martensite formation. Alternatively, data could indicate depletion of austenite in $\mathrm{C}$ during quenching and room temperature storage of the material. Nevertheless, in a study published 1 year earlier, Yeshov and Oslon followed $a^{\gamma}$ during quenching of several steel samples by probing $\{200\}_{\gamma}$ lattice planes and showed the build-up of a tensile state of stress in austenite at the beginning of the transformation, followed by relaxation of these stresses at a later stage [23]. Remarkably, later work by the same authors [22] showed that martensite formation evokes a state of tensile lattice strain in austenite for probing $\{200\}_{\gamma}$, while probing $\{111\}_{\gamma}$ showed compression. These results seem irreconcilable. However, it should be realized that for f.c.c. metals lattice strains depend non-linearly on the applied load if strained into the plastic region [29-32]. This non-linear behavior is $h k l$ dependent and yields anisotropic strains that are retained upon unloading. The $[200]_{\gamma}$ direction is elastically the most compliant and plastically the softest and therefore has the most pronounced non-linear behavior. Consequently, the $200_{\gamma}$ reflection is inappropriate for the evaluation of the average state of residual stress in f.c.c. metals subjected to plastic deformation. According to Refs. [29-31], probing $311_{\gamma}$, or averaging lattice strains over several reflections, is most appropriate. Later, reconsidering the results in Ref. [30], it was suggested that $111_{\gamma}$ or $422_{\gamma}$ are the most appropriate reflections [32]. Evidently, an incorrect choice of the reflections probed for the evaluation of the state of stress in austenite may have played a role in the discrepancy between data. The first serious attempt to solve the controversy appeared in 1974, when Golovchiner determined in situ the evolution of lattice strain in austenite versus the fraction transformed in a large number of 
ferrous alloys [13]. These alloys were fully austenitic at room temperature and largely transformed to martensite during cooling to $93 \mathrm{~K}\left(-180^{\circ} \mathrm{C}\right)$. Determination of $a^{\gamma}$ was performed based on the $311_{\gamma}$ reflection. In all investigated samples, compression was observed in austenite after martensite formation for transformed fractions beyond 10-60\%, depending on the chemical composition of the alloy.

In 1980, the focus firstly included the state of stress in martensite [14]. It was claimed that martensite formation evoked compressive stresses in both austenite and martensite. Nevertheless, this claim violates the condition that, in absence of external forces, balancing of forces should be obtained for a finite matrix [3-5]:

$\sum_{\varphi} f^{\varphi} \cdot\left\langle\sigma^{\varphi}\right\rangle=0$

with $f^{\varphi}$ volume fraction of phase $\varphi$. Hence:

$f^{\alpha^{\prime}} \cdot\left\langle\sigma^{\alpha^{\prime}}\right\rangle=-f^{\gamma} \cdot\left\langle\sigma^{\gamma}\right\rangle$

with $f^{\alpha^{\prime}}$ and $f^{\gamma}$ the volume fraction of martensite and austenite, respectively. Thus, compression in austenite should be balanced by tension in martensite. It is important to realize that the lattice strains determined in Ref. [14], departed from the assumption that stresses were null at the beginning of the transformation. This is unlikely for the minority phase, martensite (cf. Eq. 4), suggesting that the analysis may have been faulty. Additionally, data may have been affected by the presence of macro-stresses, implying that Eq. 2 could not be used. Unfortunately, similar arguments apply for all references cited above.

The need for more thorough stress analysis was firstly recognized in 1990 [15]. XRD was applied at room temperature to determine $a_{\gamma}$ (based on $220_{\gamma}$ ) in Fe-C and Fe-N thin foils. Data indicated that retained austenite experienced compressive strain in the direction perpendicular to the sample surface. To convert strain into stress, measurements were performed in various directions. Because of the shallow penetration depth of laboratory X-rays, all components of stress in martensite in the direction perpendicular to the sample surface, $\sigma_{\perp}^{\alpha^{\prime}}$, were assumed equal to zero. The principal stress component parallel to the sample surface, $\sigma_{\|}^{\alpha^{\prime}}$ was evaluated applying the $\sin ^{2} \psi$ method (cf. Ref. [4]). Data revealed that stresses in martensite were negligible within the probed volume. Since a negligible state of stress in the majority phase (i.e. martensite) does not imply that the balancing stress in the minority phase (i.e. austenite) is negligible, (cf. Eq.4) compressive strain in austenite was interpreted in terms of a state of compressive stress in this phase.

The limitations associated with the shallow penetration/information depth of laboratory X-rays could be overcome by applying Neutron diffraction [25,26] or synchrotron XRD [16-20,27]. 
119 In Refs. [25,26], $a^{\gamma}$ was measured in homogeneous Fe-Ni-C austenite as well as after partial 120 transformation of the austenite into martensite. Data indicated that martensite formation did not 121 affect $a^{\gamma}$. Similarly, San. Martin et al. followed the formation of martensite in Fe-Cr-Ni-Mo 122 maraging steel up to $40 \%$ fraction transformed and showed that the averaged value of $a^{\gamma}$ does not 123 change with $f^{\alpha^{\prime}}$ [27]. Conversely, Villa et al. showed that martensite formation during sub-zero 124 Celsius treatment of steel induces compressive lattice strain in austenite [16-18]. The application of 125 the $\sin ^{2} \psi$ method ex situ indicated that lattice strain was caused by compressive stress in austenite, 126 which was hydrostatic within the probed volume. Similarly, Epp showed that compressive 127 hydrostatic stress build up in austenite during quenching of high $\mathrm{C}$ steel $[19,20]$. Evidently, 128 diffraction experiments at large scale facilities did not provide a unanimous answer.

129 A last attempt to clarify the picture was presented in Ref. [21]. Laboratory XRD was applied to 130 measure $a^{\gamma}$ before and after martensite formation in a Fe-Ni alloy and data was complemented with 131 measurement of $a^{\gamma}$ after tempering to $523 \mathrm{~K}\left(250^{\circ} \mathrm{C}\right)$. Tempering is expected, at least partially, to 132 lead to relaxation of internal stresses. Data showed that compressive lattice strain develops in 133 austenite during martensite formation for $f^{\alpha^{\prime}}>75 \%$, and that this strain is largely annihilated during 134 tempering. No strain was observed in martensite. Compressive strain in austenite was interpreted in 135 terms of hydrostatic compressive stress in this phase.

136 Summarizing, no consistent picture exists of the evolution of stress in austenite and martensite 137 during martensite formation in steel. Careful evaluation of the discussed literature reveals that 138 during martensite formation a state of compressive stress builds-up in austenite. The compression is 139 observed by XRD only after a threshold fraction of austenite has transformed to martensite and 140 appears hydrostatic when averaged over the probed volume. The internal stress in austenite is 141 interpreted as micro-stress of type II, but this hypothesis has never been verified with the 142 simultaneous observation of balancing tensile micro-stress of type II in martensite. Tempering may 143 promote relaxation of stresses and give indication on their actual presence. In the present work, 144 experiments were designed to investigate the evolution of phase specific stresses in both austenite 145 and martensite during quenching and tempering of steel.

147 The material selected for investigation was commercial EN 1.4418 steel (Table 1), which is a soft 148 martensitic stainless steel grade, with a low fraction of interstitials. Martensite in this alloy is body 149 centered cubic b.c.c. and has lath morphology [33,34]. The martensite start temperature, $M_{s}$, equals $408 \mathrm{~K}\left(135^{\circ} \mathrm{C}\right)[34]$ and the Curie temperature, $T_{C}$, of martensite equals $898 \mathrm{~K}\left(625^{\circ} \mathrm{C}\right)[34]$. 
151 Two Ø10 mm x $0.15 \mathrm{~mm}$ disks, labelled sample 1 and sample 2, respectively, were prepared for 152 synchrotron XRD investigation. Preparation comprised austenitization at $1223 \mathrm{~K}\left(950{ }^{\circ} \mathrm{C}\right)$ for 10 $153 \mathrm{~min}$ in a continuous flow of Ar gas, followed by cooling to room temperature at an average rate of 154 approx. $1 \mathrm{~K} \mathrm{~s}^{-1}$. Thereafter, samples were ground and electro-polished for $5 \mathrm{~s}$ at $40 \mathrm{~V}$ in Struers A-2 electrolyte. The condition of the material after preparation is labelled "as normalized".

Energy-dispersive XRD investigation was performed in situ at the EDDI beamline of the BESSY II synchrotron facility [35]. In Energy dispersive XRD, the investigation is carried out using a beam of white X-rays at a fixed diffraction angle, $2 \theta$, and diffraction for crystallographic planes, $\{h k l\}$, will occur at a photon energy, $E^{h k l}$. The energy position, $E^{h k l}$, of the diffraction lines in the energy spectrum is inversely proportional to the interplanar spacing, $d^{h k l}[36]$ :

$E^{h k l}=\frac{h c}{2 \sin \theta} \cdot \frac{1}{d^{h k l}}:$

with $h$ Planck's constant and $c$ the speed of light. The average information depth for each diffraction line is a function of its energy, and of the diffraction geometry applied [37].

In the present investigation, the acquisition time was set to $60 \mathrm{~s}$ per spectrogram (i.e. diffractogram) and the experiments were conducted with a $0.5 \times 0.5 \mathrm{~mm}^{2}$ slit configuration on the primary side applying the diffraction geometry $\theta-2 \theta=7^{\circ}-14^{\circ}$. The equatorial slit aperture was set to 0.03 $\mathrm{mm}$. Two configurations were applied: in the first, the scattering vector was kept perpendicular to the sample surface; in the second, the angle between the scattering vector and the surface normal, $\psi$, was varied by tilting the sample around an axis parallel to the plane through incident and diffracted beam ( $\sin ^{2} \psi$ method). The experimental setup is presented in Fig. 1.

Diffraction lines were fitted with pseudo-Voigt profile functions. Each reflection was analyzed independently to account for anisotropic lattice strain. A gold reference standard was used for calibration of the absolute value of the lattice parameter. The quantification of $f^{\gamma}$ and $f^{\alpha^{\prime}}$ was based on a direct comparison of the integrated intensity of the diffraction peaks of austenite and martensite [38]. Additional details were given in Ref. [33]. The analysis included the $200_{\gamma}, 220_{\gamma}$, $311_{\gamma}$ and $222_{\gamma}$ reflections of austenite and the $200_{\alpha^{\prime}}, 211_{\alpha^{\prime}}, 220_{\alpha^{\prime}}$ and $321_{\alpha^{\prime}}$ reflections of martensite. The $111_{\gamma} / 110_{\alpha^{\prime}}$ couple was excluded because these reflections largely overlap and because these line profiles correspond to the lowest information depth among all reflections and, thus, are most sensitive for surface effects. 

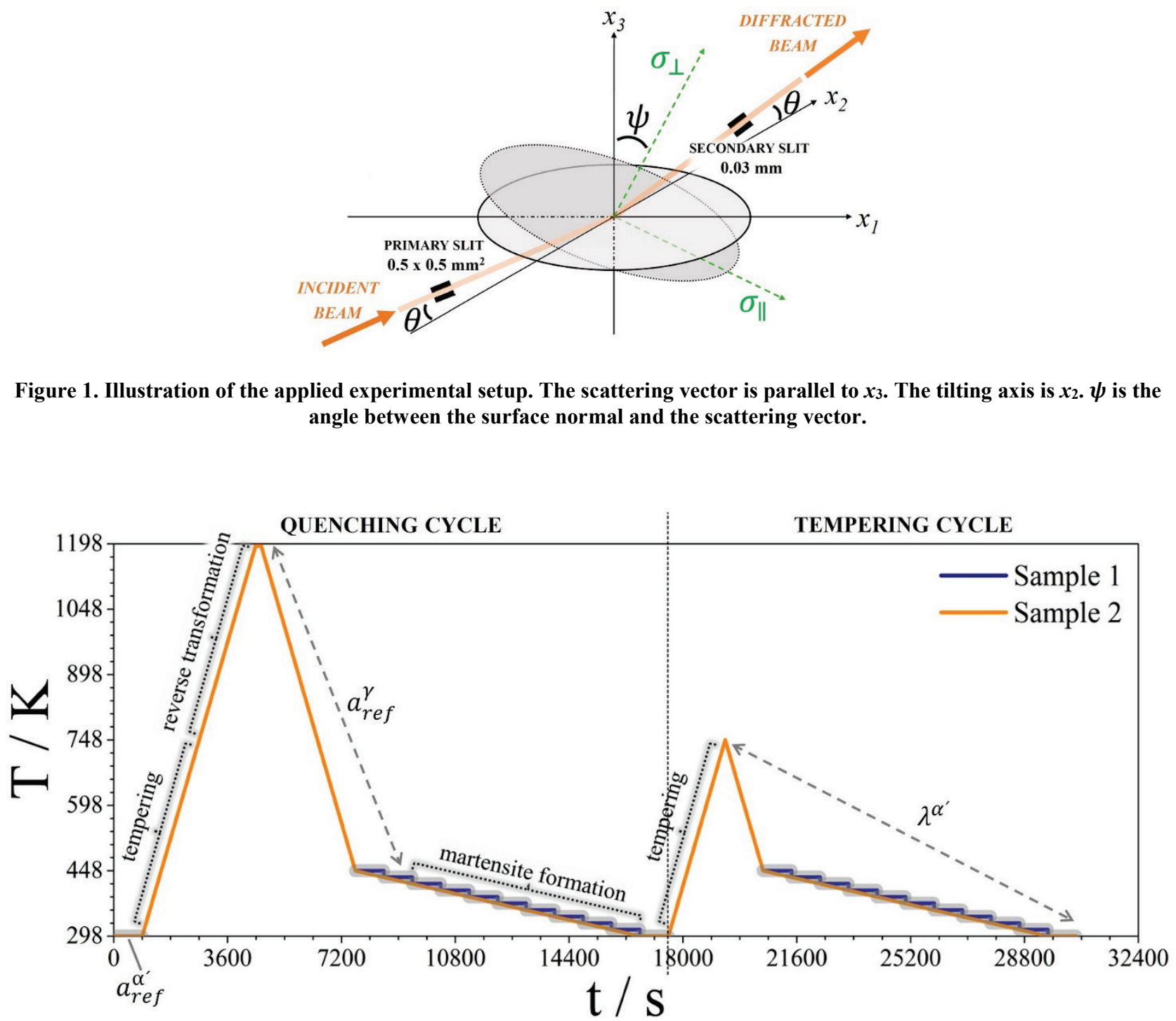

Figure 2. Schematic representation of the thermal cycle applied during the XRD investigation and of the various transformations occurring in the material. The graph also indicates the data which were used to estimate the reference values of the lattice parameters of austenite and martensite (see section 3.1.).

Investigation was performed in an Anton Paar DHS 1100 Domed Hot Stage under continuous flow of protective Ar gas at a constant pressure of 1.4 bar. The samples were placed on the heating element (alumina plate) onto which they were secured by mild clamping. The temperature was measured with a Pt-Pt10Rh thermocouple fixed to the stage.

194 The thermal cycle consisted of a quenching step, immediately followed by a tempering step and it is 195 illustrated in Fig. 2. During the quenching step, samples were heated to $1193 \mathrm{~K}\left(920^{\circ} \mathrm{C}\right)$ at a rate of $0.25 \mathrm{~K} \mathrm{~s}^{-1}$, austenitized for $180 \mathrm{~s}$, and cooled to $448 \mathrm{~K}\left(175^{\circ} \mathrm{C}\right)$ at the same rate. Cooling from 448 $\mathrm{K}\left(175^{\circ} \mathrm{C}\right)$ to room temperature was performed at an average rate of $0.017 \mathrm{~K} \mathrm{~s}^{-1}$. The tempering step consisted of heating the samples to $748 \mathrm{~K}\left(475^{\circ} \mathrm{C}\right)$ at a rate of $0.25 \mathrm{~K} \mathrm{~s}^{-1}$ followed by continuous cooling under the same experimental conditions applied during quenching. The cooling steps from $448 \mathrm{~K}\left(175^{\circ} \mathrm{C}\right)$ to room temperature were carried out as follows: sample 1 was cooled in 
steps of $15 \mathrm{~K}$ maintaining an overall average cooling rate of $0.017 \mathrm{~K} \mathrm{~s}^{-1}$ and $\psi$, was varied from $0^{\circ}$ to $72^{\circ}$ in steps of $8^{\circ}$ at each investigation temperature (in $\operatorname{situ} \sin ^{2} \psi$ method); sample 2 was continuously cooled at a rate of $0.017 \mathrm{~K} \mathrm{~s}^{-1}$ and $\psi$ was maintained equal to $0^{\circ}$. Additionally, the $\sin ^{2} \psi$ method was applied ex situ at the beginning of the thermal cycle and at the end of the investigation.

\section{Results and interpretation}

\subsection{Evaluation of lattice strains and stress analysis}

The calculation of lattice strains in austenite, $\varepsilon_{\psi}^{h k l_{\gamma}}$, and martensite, $\varepsilon_{\psi}^{h k l_{\alpha^{\prime}}}$, from Eq.1 requires that the strain-free lattice parameter of austenite, $a_{r e f}^{\gamma}$, and of martensite, $a_{r e f}^{\alpha^{\prime}}$, are known as a function of temperature.

211 The value of $a_{r e f}^{\gamma}$ was obtained by extrapolating a second order polynomial fitted through $a_{\perp}^{\gamma}$ 212 (averaged over all $h \mathrm{kl}$ ) as measured during cooling in the temperature interval 418-1193 K (145-920 $213{ }^{\circ} \mathrm{C}$ ), where austenite is the only phase present because $\mathrm{T}>\mathrm{M}_{\mathrm{s}}$. In particular, $\lambda^{\gamma}=1.285 \cdot 10^{-5}+$ $2141.052 \cdot 10^{-8} T-4.677 \cdot 10^{-12} T^{2}$, with $\mathrm{T}$ temperature expressed in $\mathrm{K}$, which is consistent with 215 literature data for austenitic stainless steels in the same temperature interval [45].

216 A similar experimental condition for $a_{r e f}^{\alpha^{\prime}}$, where martensite is the only phase present in the sample, 217 is not available. Therefore, the value of $a_{r e f}^{\alpha^{\prime}}$ at $298 \mathrm{~K}\left(25^{\circ} \mathrm{C}\right)$ was calculated under the condition 218 of balancing micro-stresses of type II (cf. Eq.4) at the beginning of investigation. The value of $a_{r e f}^{\alpha^{\prime}}$ 219 for the temperature interval $298-898 \mathrm{~K}\left(25-625^{\circ} \mathrm{C}\right)$ was calculated from $a_{r e f}^{\alpha^{\prime}}$ at $298 \mathrm{~K}\left(25^{\circ} \mathrm{C}\right)$ and 220 the coefficient of thermal expansion of strain-free martensite, $\lambda^{\alpha^{\prime}}=1.266 \cdot 10^{-5} K^{-1}$, as evaluated 221 by fitting $a_{\perp}^{\alpha^{\prime}}$ as measured during cooling tempered martensite from $748 \mathrm{~K}\left(475^{\circ} \mathrm{C}\right)$ to room temperature. This is consistent with literature data for martensitic stainless steel in the same temperature interval [45]. For $\mathrm{T}>898 \mathrm{~K}\left(625^{\circ} \mathrm{C}\right)$, martensite is paramagnetic and $\lambda^{\alpha^{\prime}}$ evaluated for ferromagnetic martensite does no longer apply [45]. This is beyond the scope of the present work. Lattice strains were converted into stresses. During all thermal steps where $\psi=0$, the average stresses in the phases, $\left\langle\sigma^{\varphi}\right\rangle$, could be determined only under the assumption that the samples are free from macro-stresses (cf. Eq. 2). Unfortunately, this assumption does not apply in the present case, as will be shown in section 3.3.

In a thin sample, macro-stresses can be considered relaxed, and thus equal to zero, in the direction normal to the sample surface, $\perp$. In the direction parallel to the sample surface, $\|$, macro-stresses 
231 balance over the sample cross section, but are not necessarily balanced within the volume of 232 material probed by XRD, and can thus deviate from zero.

233 To account for the possible presence of macro-stresses, lattice strains were measured in sample 1 at 234 several $\psi$ angles at fixed temperature. This procedure was applied only to the part of the thermal 235 cycle of most interest for the current investigation. Stresses were determined under the assumption 236 of rotational symmetry within the plane of the sample and the stress components $\sigma_{\|}^{\varphi}-\sigma_{\perp}^{\varphi}$ and $\sigma_{\perp}^{\varphi}$ 237 were calculated applying the $\sin ^{2} \psi$ method. Assuming that the stress is rotationally symmetric, the 238 lattice strain is given by [4]:

$\varepsilon_{\psi}^{h k l_{\varphi}}=S_{1}^{h k l_{\varphi}}\left[2 \cdot \sigma_{\|}^{\varphi}+\sigma_{\perp}^{\varphi}\right]+\frac{1}{2} S_{2}^{h k l_{\varphi}} \cdot \sigma_{\perp}^{\varphi}+\frac{1}{2} S_{2}^{h k l_{\varphi}}\left[\sigma_{\|}^{\varphi}-\sigma_{\perp}^{\varphi}\right] \cdot \sin ^{2} \psi$

240 The XEC $S_{1}^{h k l_{\varphi}}$ and $\frac{1}{2} S_{2}^{h k l_{\varphi}}$ (Table 2) were calculated from the single crystal elastic constants for 241 ferrite [39] and austenite [40] $]^{\dagger}$ applying the Eshelby/Kröner model for elastic grain interaction $242[41,42]^{+}$and the material is assumed free of texture.

243 For Energy Dispersive XRD, and under the assumption that macro-stresses in the $\perp$ direction are 244 null, the slope of the dependence of lattice strain, $\varepsilon_{\psi}^{h k l_{\varphi}}$, on $\sin ^{2} \psi$ provides $\sigma_{\|}^{\varphi}-\sigma_{\perp}^{\varphi}$ while the 245 intercept equals $S_{1}^{h k l_{\varphi}}\left[2 \cdot \sigma_{\|}^{\varphi}+\sigma_{\perp}^{\varphi}\right]+\frac{1}{2} S_{2}^{h k l_{\varphi}} \cdot \sigma_{\perp}^{\varphi}$. The equations for slope and intercept provide 246 the set of equations to assess the individual values of $\sigma_{\|}^{\varphi}$ and $\sigma_{\perp}^{\varphi}$, provided that the XECs are 247 known. The macro-stress $\sigma_{\|}^{\varphi}-\sigma_{\perp}^{\varphi}$ (of type I) in phase $\varphi$ corresponds to an $h k l$-dependent depth, $248 \zeta^{h k l}$, and $\sigma_{\perp}^{\varphi}$ represents the average micro-stresses of type II in $\varphi$. From Eq.3 it is obtained:

$249 \quad \sum_{\phi} \mathrm{f}^{\varphi} \cdot\left\langle\sigma_{\perp}^{\varphi}\right\rangle=0$

250 where $\left\langle\sigma_{\perp}^{\varphi}\right\rangle$ represents the stress averaged over all investigated $h k l$ for phase $\varphi .{ }^{\S}$

251 In the present case, $\zeta^{h k l}$ can be estimated using the absorption coefficient of Fe for the appropriate 252 energy and equals to approx. $4 \mu \mathrm{m}, 5 \mu \mathrm{m}, 14 \mu \mathrm{m}, 22 \mu \mathrm{m}$ and $25 \mu \mathrm{m}$ for the $111_{\gamma}, 200_{\gamma}, 220_{\gamma}$, $253311_{\gamma}$ and $222_{\gamma}$ reflections of austenite, respectively, and approx. $4 \mu \mathrm{m}, 10 \mu \mathrm{m}, 18 \mu \mathrm{m}, 27 \mu \mathrm{m}$ and $25455 \mu \mathrm{m}$ for the $110_{\alpha^{\prime}} 200_{\alpha^{\prime}}, 211_{\alpha^{\prime}}, 220_{\alpha^{\prime}}$ and $321_{\alpha^{\prime}}$ reflections of martensite, respectively.

\footnotetext{
$\dagger$ The bulk elastic modulus of austenite, $B^{\gamma}$, and of martensite, $B^{\alpha}$ calculated from Refs. [51,52] are $184 \mathrm{GPa}$ and 167 $\mathrm{GPa}$, respectively. From Ref. [56], for $\mathrm{Fe}-15 \% \mathrm{Cr}-5 \% \mathrm{Ni} B^{\gamma}=164 \mathrm{GPa}$ and is not significantly affected by the presence of interstitials. [57] This indicates that Ref. [52] most likely overestimated the stiffness of austenite. No accurate information is available to evaluate the value of $B^{\alpha}$ from Ref. [51].

$\$$ It should be noted that the Eshelby/Kröner model for the present case is an approximation, as it assumes elastic interaction of crystals with identical elastic constants, while the present material is two phase with different elastic constants for the two phases.

$\S$ The multiplicity of the various $h k l$ was not taken into account, implying that all reflections was equally weighted.
} 


\subsection{Evolution of phase fraction and lattice strain during thermal cycling}

\subsubsection{Phase fraction}

257 The evolution of the fraction of martensite as measured for diffraction vector perpendicular to the surface, $f_{\perp}^{\alpha^{\prime}}$, is shown in Fig. 3a versus temperature, T. Data plotted in Fig. 3a represents the average value over the two investigated samples and is only representative of the fraction of

martensite in the material, $f^{\alpha^{\prime}}$, for the (unlikely) assumption of random grain orientation [46].

261 At the beginning of the investigation $f_{\perp}^{\alpha^{\prime}}$ is 0.93 (Fig. 3a). During heating, reverse austenite 262 formation starts at about $823-848 \mathrm{~K}\left(550-575^{\circ} \mathrm{C}\right)$. Austenitization proceeds in two steps and is completed just below $1193 \mathrm{~K}\left(920^{\circ} \mathrm{C}\right)$. Two-step kinetics of reverse austenite formation in soft martensitic stainless steel is discussed in detail elsewhere $[33,34,47]$

265 On cooling from the austenitization temperature, martensite is firstly observed at $703 \mathrm{~K}\left(330^{\circ} \mathrm{C}\right)$, 266 approx. $200 \mathrm{~K}$ above $M_{S}$, by appearance of the $110_{\alpha^{\prime}}$ line profile, which is probed at the lowest 267 average information depth of all $h k l s$. On continued cooling, the intensity of $110_{\alpha^{\prime}}$ increases and is 268 accompanied by $200_{\alpha^{\prime}}, 211_{\alpha^{\prime}}, 220_{\alpha^{\prime}}$ and $321_{\alpha^{\prime}}$ in the order of mentioning, consistent with a gradual increase of the information depth $\zeta^{h k l}$. Evidently, martensite formation starts at $703 \mathrm{~K}(330$ ${ }^{\circ} \mathrm{C}$ ) in the near surface region and progresses in the depth direction on continued cooling. It has repeatedly been reported that the formation of lath martensite starts at the free surface at a

272 temperature significantly higher than $M_{s}$ [47-52]. The present results are fully consistent with these 273 observations.

274 The martensite content $f_{\perp}^{\alpha^{\prime}}$ exceeded 0.03 at about $403 \mathrm{~K}\left(130{ }^{\circ} \mathrm{C}\right)$, which is below $M_{s}$. Thereafter, 275 on continued cooling, a large fraction of martensite formed within the temperature range $383-353 \mathrm{~K}$ $276\left(115-85^{\circ} \mathrm{C}\right)$ followed by martensite formation at a progressively reduced rate. At $298 \mathrm{~K}\left(25^{\circ} \mathrm{C}\right)$, 277 about $93 \%$ of the austenite had transformed into martensite, consistent with the starting condition. 278 Upon quenching, the material was tempered to $748 \mathrm{~K}\left(475^{\circ} \mathrm{C}\right)$ without affecting the fraction of 279 martensite in the sample. 


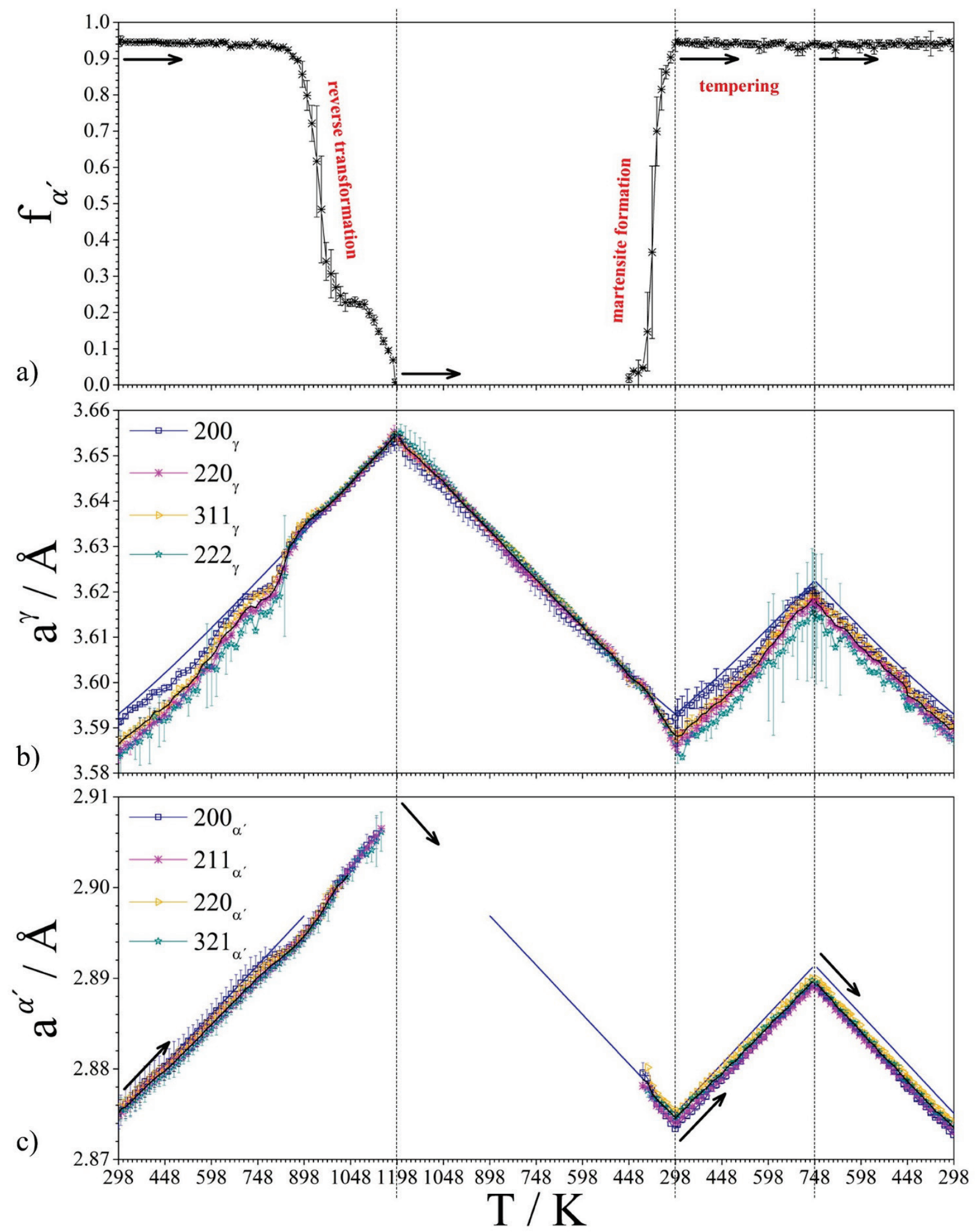

Figure 3. a) Fraction of martensite evaluated in the direction normal to the sample surface $f_{\perp}^{\alpha^{\prime}}$ plotted versus temperature $T$ (values represent average values for sample 1 and sample 2; the error bars are the standard deviation); b) lattice parameter of austenite measured in the direction normal to the sample surface $a_{\perp}^{\gamma}$ plotted versus temperature T; c) lattice parameter of martensite measured in the direction normal to the sample surface $a_{\perp}^{\alpha^{\prime}}$ plotted versus temperature T. The blue continuous lines in b) and c) represent the strain free lattice parameter of the phases $a_{r e f}^{\varphi}$. The black continuous lines in b) and c) show the value of the lattice parameter of the phases $a_{r e f}^{\varphi}$ averaged over the probed reflections, not including $20 \alpha_{\alpha^{\prime}}$. In order to compare between the two data sets, 1 data point every $15 \mathrm{~K}$ is considered for sample 2 when cooled within the temperature range $298 \mathrm{~K}<\mathrm{T}<448 \mathrm{~K}\left(25^{\circ} \mathrm{C}<\mathrm{T}<175^{\circ} \mathrm{C}\right)$. 


\subsubsection{Lattice strains}

291 The lattice parameters calculated from the lattice spacing for $\{h k l\}$ are given for austenite in Fig. $3 b$ 292 and for martensite in Fig. 3c. The evolutions of lattice strains in these phases are described 293 separately below.

\section{Austenite}

295 At the beginning of the quenching cycle, $a^{\gamma}$ was significantly smaller than $a_{r e f}^{\gamma}$ (given by the 296 drawn blue line) and varies with the $h k l$ probed, which indicates that austenite experiences anisotropic compressive lattice strain in the direction $\perp$.

298 On heating, $a^{\gamma}$ expands at a ( $h k l$-dependent) rate which deviates from the value expected from the thermal expansion coefficient $\lambda_{\gamma}$, indicating changes in lattice strain, $\varepsilon_{\perp}^{h k l_{\gamma}}$. Compressive lattice 300 strains $\varepsilon_{\perp}^{h k l_{\gamma}}$ increase up to $523 \mathrm{~K}\left(250^{\circ} \mathrm{C}\right)$, decrease in the temperature range 523-748 $\mathrm{K}(250-475$ $\left.301{ }^{\circ} \mathrm{C}\right)$, where after they increase again up to $798 \mathrm{~K}\left(525^{\circ} \mathrm{C}\right)$, and eventually are annihilated at about $848 \mathrm{~K}\left(575^{\circ} \mathrm{C}\right)$, when the reverse austenite formation commences.

On cooling, $a^{\gamma}=a_{r e f}^{\gamma}$ for $T \geq 418 K\left(145^{\circ} \mathrm{C}\right)$ (by definition), implying that $\varepsilon_{\perp}^{h k l_{\gamma}}=0$. Thereafter, for temperatures below $M_{s}, a^{\gamma}<a_{r e f}^{\gamma}$, which indicates that martensite formation is accompanied by compressive lattice strain in austenite in the direction perpendicular to the surface. The observed lattice strain is largest at $298 \mathrm{~K}\left(25^{\circ} \mathrm{C}\right)$ and depends on $h k l$ : the largest $\varepsilon_{\perp}^{h k l_{\gamma}}$ is observed for $220_{\gamma}$ and $222_{\gamma}$, while $\varepsilon_{\perp}^{h k l_{\gamma}}$ is negligible for $200_{\gamma}$ and for $311_{\gamma}$ it shows a value close to the average over $h k l$. This behaviour for the various $h k l$ is analogous to the dependence on $h k l$ for the starting condition.

310 On tempering, the evolution of $\varepsilon_{\perp}^{h k l_{\gamma}}$ during heating to $748 \mathrm{~K}\left(475^{\circ} \mathrm{C}\right)$ reflects the same trends as 311 on heating the "as normalized" condition. On reaching $748 \mathrm{~K}\left(475{ }^{\circ} \mathrm{C}\right)$, about half the compressive 312 lattice strain evoked in austenite during quenching has relaxed, assuming that no change in 313 composition occurred. On cooling to $298 \mathrm{~K}\left(25^{\circ} \mathrm{C}\right)$, no additional changes of $\varepsilon_{\perp}^{h k l_{\gamma}}$ are observed. 314 Data is largely consistent with recent work in the literature [53], and indicates that residual stresses 315 in austenite are partially relaxed during tempering of martensitic stainless steel to $748 \mathrm{~K}\left(475^{\circ} \mathrm{C}\right)$.

Martensite

317 At the beginning of the investigation, $a^{\alpha^{\prime}} \approx a_{r e f}^{\alpha^{\prime}}$, which implies that $\varepsilon_{\perp}^{\alpha^{\prime}} \approx 0$.

318 On heating, the measurement of $a^{\alpha^{\prime}}$ shows four distinct regimes: 
- for $\mathrm{T}<423 \mathrm{~K}\left(150{ }^{\circ} \mathrm{C}\right)$, the rate of expansion of the unit cell of martensite is consistent with $\lambda_{\alpha^{\prime}}$

- for the temperature range $423-748 \mathrm{~K}\left(150-475^{\circ} \mathrm{C}\right), a^{\alpha^{\prime}}$ expands at a rate that varies with $h k l$ and in general is smaller than $\lambda_{\alpha^{\prime}}$;

- for temperatures in the range $748-898 \mathrm{~K}\left(475-625^{\circ} \mathrm{C}\right)$ a significant difference between $a^{\alpha^{\prime}}$ and $a_{r e f}^{\alpha^{\prime}}$ yields a large deviation between the observed and predicted lattice parameter at $898 \mathrm{~K}\left(625^{\circ} \mathrm{C}\right)$;

- at $898 \mathrm{~K}\left(625^{\circ} \mathrm{C}\right)$, martensite becomes paramagnetic and $\lambda_{\alpha^{\prime}}$ increases significantly.

On cooling, martensite reflections have sufficient intensity for a temperature of $403 \mathrm{~K}\left(130{ }^{\circ} \mathrm{C}\right)$, when approx. $5 \%$ of the austenite has transformed. For fractions up to $f_{\perp}^{\alpha} \approx 0.2$, data scatters significantly. For martensite fractions beyond 0.2 , the lattice strain in martensite varies significantly depending on the probed $h k l$. On average, $a_{\perp}^{h k l_{\alpha^{\prime}}}<a_{\text {ref }}^{\alpha^{\prime}}$ and about constant over the whole transformation process.

During tempering, the evolution of $a_{\perp}^{\alpha^{\prime}}$ on heating to $748 \mathrm{~K}\left(475^{\circ} \mathrm{C}\right)$ is consistent with the data obtained on heating the sample "as normalized" and the lattice of martensite expands less than predicted based on $\lambda_{\alpha^{\prime}}$ in the temperature interval $448-748 \mathrm{~K}\left(175-475^{\circ} \mathrm{C}\right)$. This deviation is retained on subsequent cooling to $298 \mathrm{~K}\left(25^{\circ} \mathrm{C}\right)$.

Data acquired during the two heating steps indicates that tempering of martensite proceeds in two stages in this alloy: the first stage extends from $423 \mathrm{~K}\left(150^{\circ} \mathrm{C}\right)$ to $623 \mathrm{~K}\left(350^{\circ} \mathrm{C}\right)$; the second stage from $748 \mathrm{~K}\left(475^{\circ} \mathrm{C}\right)$ to $898 \mathrm{~K}\left(625^{\circ} \mathrm{C}\right)$. Data is consistent with previous work in the literature [53] and could either be interpreted in terms of the introduction of compressive lattice strains, $\varepsilon_{\perp}^{h k l_{\alpha}{ }^{\prime}}$, in martensite or as the rejection of $\mathrm{C}$ and $\mathrm{N}$ from solid solution. Applying the unit cell volumes for $\mathrm{Fe}-$ $\mathrm{C}$ and Fe-N martensite from Ref. [15], ${ }^{* *}$ and assuming that $\varepsilon_{\perp}^{h k l_{\alpha^{\prime}}}$ is not affected by tempering, the observed differences between the variation of $a_{\perp}^{\alpha^{\prime}}$ with temperature and $\lambda_{\alpha^{\prime}}$ would correspond to the rejection of approx. $0.03 \mathrm{wt} \% \mathrm{C}+\mathrm{N}$ during the first stage of tempering and $0.04 \mathrm{wt} \% \mathrm{C}+\mathrm{N}$ during the second stage. These values are considered realistic taking into account the alloy composition (cf. Table 1), and imply that the effect of tempering on $a_{\perp}^{\alpha^{\prime}}$ can mainly have its origin in a change of the content of interstitials in solid solution in martensite.

\subsection{State of stress - sample 1}

\footnotetext{
${ }^{* *}$ Note that the relative difference between the effects of $\mathrm{C}$ and $\mathrm{N}$ (in wt $\%$ ) on the unit cell volume of martensite is $<3$ $\%$, and can be neglected within the experimental accuracy indicated in Ref. [15].
} 

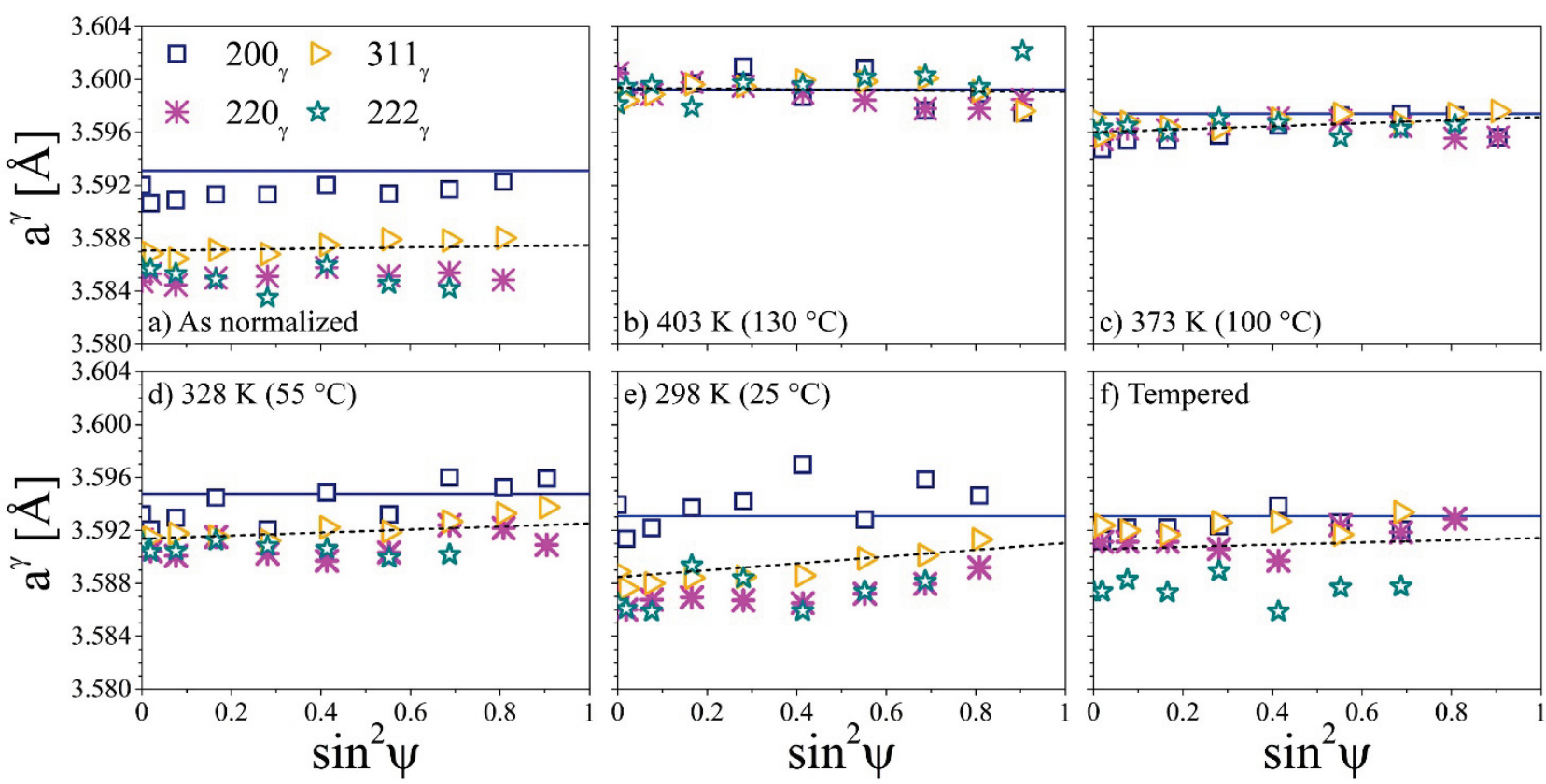

Figure 4. Lattice parameter of austenite $a^{\gamma}$ evaluated from $200_{\gamma}, 311_{\gamma}, 220_{\gamma}$ and $222_{\gamma}$ and plotted versus $\sin ^{2} \psi$. Data acquired: (a) at the beginning of the investigation; (b) at $403 \mathrm{~K}\left(130{ }^{\circ} \mathrm{C}\right)$ during quenching; (c) at $373 \mathrm{~K}\left(100{ }^{\circ} \mathrm{C}\right)$ during quenching; (d) at $328 \mathrm{~K}\left(55^{\circ} \mathrm{C}\right)$ during quenching; (e) at the end of the quenching cycle; (f) at room temperature after tempering to $748 \mathrm{~K}\left(475^{\circ} \mathrm{C}\right)$. The blue continuous lines represent the strain-free lattice parameter of austenite $a_{r e f}^{\gamma}$. The
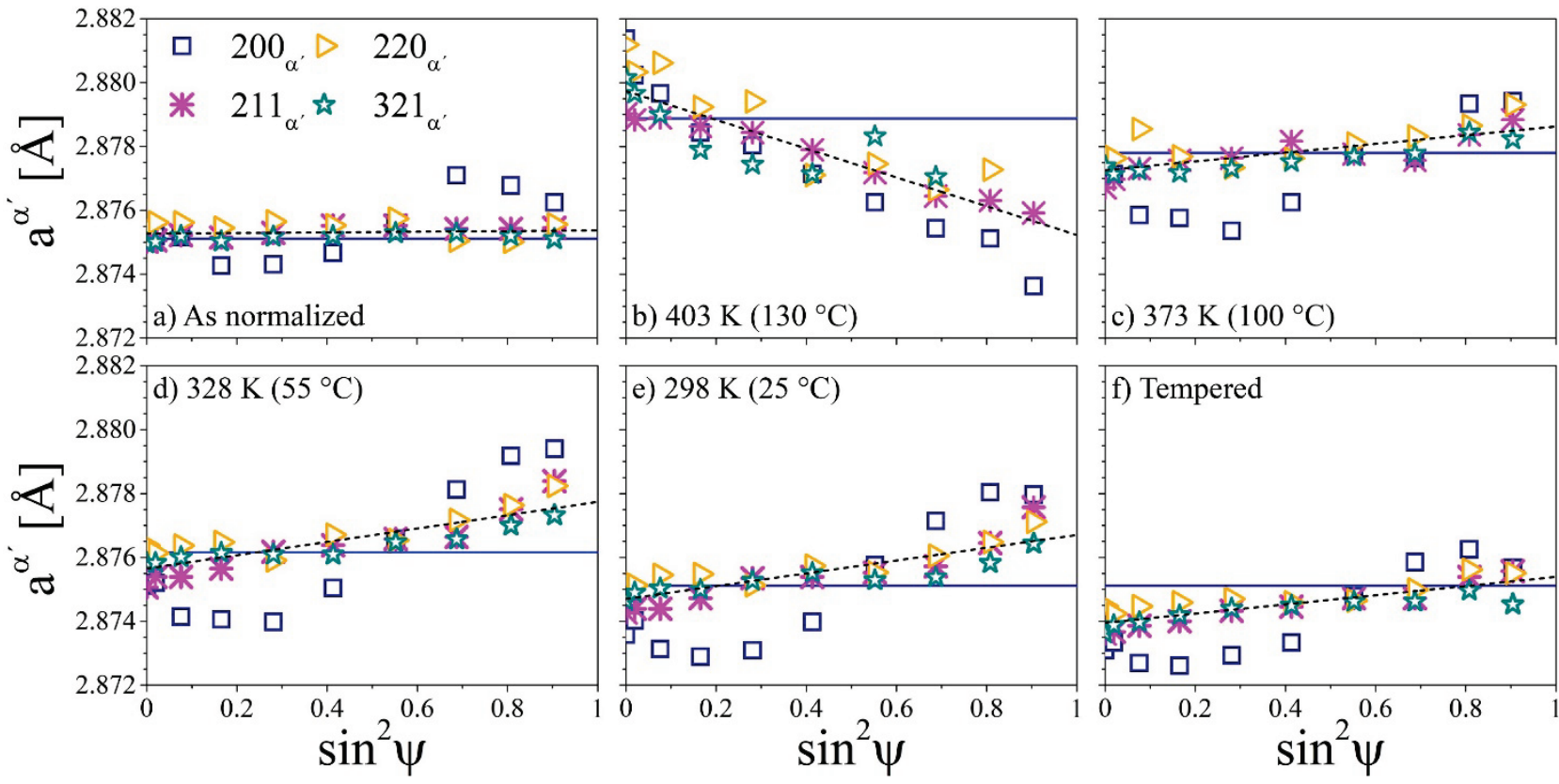

Figure 5. Lattice parameter of martensite $a^{\alpha^{\prime}}$ evaluated from $20 \alpha_{\alpha^{\prime}}, 211_{\alpha^{\prime}}, 220_{\alpha^{\prime}}$ and $321_{\alpha^{\prime}}$ and plotted versus $\sin ^{2} \psi$. Data acquired: (a) at the beginning of the investigation; (b) at $403 \mathrm{~K}\left(130{ }^{\circ} \mathrm{C}\right)$ during quenching; (c) at $373 \mathrm{~K}\left(100{ }^{\circ} \mathrm{C}\right)$ during quenching; (d) at $328 \mathrm{~K}\left(55^{\circ} \mathrm{C}\right)$ during quenching; (e) at the end of the quenching cycle; (f) after tempering to $748 \mathrm{~K}(475$ $\left.{ }^{\circ} \mathrm{C}\right)$. The blue continuous lines represent the strain free lattice parameter of martensite $a_{r e f}^{\alpha^{\prime}}$. The black dashed lines were 
364 In the normalized condition the steel contains a martensite fraction $f^{\alpha^{\prime}}=0.95$; the rest is retained austenite. Representative values of $a^{\gamma}$ and $a^{\alpha^{\prime}}$, determined from various $h k l$ are presented as a function of $\psi$ in Figs. 4a and 5a, respectively. Some data points at high $\psi$ angles were excluded because the diffracted intensity was insufficient for accurate peak fitting.

Fig. 4a shows that, within experimental accuracy, $a^{\gamma}$ is independent of $\psi$, indicating that the state of stress is effectively hydrostatic (or, trivially, nil), but depends on $h k l$. Comparing $a^{\gamma}$ with $a_{r e f}^{\gamma}$ (the latter as represented by the solid blue line in Fig. 4a) reveals that austenite experiences a $h k l$ dependent compressive lattice strain. Compressive strain is largest for $220_{\gamma}$ and $222_{\gamma}$, very small for $200_{\gamma}$, while compression for $311_{\gamma}$ is close to the value obtained from averaging over all measured $h k l$. Stress analysis yields $\sigma_{\|}^{\gamma}-\sigma_{\perp}^{\gamma} \approx 0$ and $\sigma_{\perp}^{\gamma}$ equal to $-0.21 \mathrm{GPa},-1.22 \mathrm{GPa}$, $-0.85 \mathrm{GPa}$ and $-1.29 \mathrm{GPa}$ for probing $200_{\gamma}, 220_{\gamma}, 311_{\gamma}$ and $222_{\gamma}$, respectively, giving an average stress value $\left\langle\sigma^{\gamma}\right\rangle=-0.89 \mathrm{GPa}$. It is noted that the order of increasing lattice strain (and associated elastic residual stress), coincides with an increase of the orientation parameter $3 \Gamma=3$. $\frac{h^{2} k^{2}+k^{2} l^{2}+l^{2} h^{2}}{\left(h^{2}+k^{2}+l^{2}\right)^{2}}$, which varies from 0 for $200_{\gamma}$ to 1 for $222_{\gamma}$ and for $311_{\gamma}$ is about half-way the range $(3 \Gamma=0.47)$, consistent with $311_{\gamma}$ representing the average over all $h k l$. This would suggest that the observed differences for the probed $h k l$ s are a consequence of elastic anisotropy in austenite. This contrasts with the zero slope in Fig. 4a., because for a hydrostatic state of stress no dependence of (elastic) lattice strain over $h k l$ would be expected. In fact, $\left[3 \cdot s_{1}^{h k l_{\varphi}}+\frac{1}{2} S_{2}^{h k l_{\varphi}}\right]$, cf. Eq.1, is independent of $h k l$, as can be verified for the data in Table 2. Evidently, the state of stress in austenite is hydrostatic within the probed volume, but not necessarily hydrostatic over the length scale of a single austenite grain (cf. Refs. $[19,20])$.

Fig. 5a shows that $a^{\alpha^{\prime}}$ evaluated from $211_{\alpha^{\prime}}, 220_{\alpha^{\prime}}$ and $321_{\alpha^{\prime}}$ neither varies with $\psi$ nor with $h k l$ within experimental accuracy. In contrast, the $\sin ^{2} \psi$ dependence of $a^{\alpha^{\prime}}$ derived from $200_{\alpha^{\prime}}$ is characterized by oscillations (cf. Ref. [4]) and therefore excluded from the analysis. Stress analysis based on $211_{\alpha^{\prime}}, 220_{\alpha^{\prime}}$ and $321_{\alpha^{\prime}}$ showed that $\sigma_{\|}^{\alpha^{\prime}}-\sigma_{\perp}^{\alpha^{\prime}} \approx 0$. The average phase specific (hydrostatic) stress in martensite calculated with Eq.4 is $\left\langle\sigma^{\alpha^{\prime}}\right\rangle=0.04 \mathrm{GPa}$.

\subsubsection{Stress developing on martensite formation}

Representative examples of lattice parameter $a_{\psi}^{\varphi}$ versus $\sin ^{2} \psi$ data, as obtained with in situ application of the $\sin ^{2} \psi$ method, are reported in Figs. 4b-e and Figs. 5b-e. Stress values were derived from such $a_{\psi}^{\varphi}$ versus $\sin ^{2} \psi$ relations, applying the XECs from Table 2. The stress values 
obtained are given in Figs. 6 and 7 as a function of $f^{\alpha^{\prime}}$. The fraction of transformed austenite was determined by averaging the values of $f_{\psi}^{\alpha^{\prime}}$ measured at all the applied tilting angles, $\psi$. This procedure reduces significantly the uncertainty caused by crystallographic texture [46]. Figures 6a and 7a show the stresses in austenite and martensite as determined in the $\perp$ direction. These stresses are interpreted as phase specific micro-stresses of type II. Figures $6 \mathrm{~b}$ and $7 \mathrm{~b}$ illustrate the difference between the stress components in the $\|$ and $\perp$ directions versus $f^{\alpha^{\prime}}$. These stresses are interpreted as macro-stresses of type I, for austenite (Fig. 6a) and martensite (Fig. 7a), respectively.

From Fig. 4, it follows that as long as martensite is the minority phase in the sample, i.e. for $T \geq$ $388 K\left(115^{\circ} \mathrm{C}\right)$, the lattice parameter for austenite is about the reference value, $a_{\psi}^{\gamma} \approx a_{\text {ref }}^{\gamma}$, implying that $\varepsilon_{\psi}^{h k l_{\gamma}} \approx 0$ (Fig. 4b). At $373 \mathrm{~K}\left(100^{\circ} \mathrm{C}\right)$, a small compressive lattice strain develops in austenite (Fig. 4c). This lattice strain increases on further cooling (Figs. 4c-e) and is most pronounced at $298 \mathrm{~K}\left(25^{\circ} \mathrm{C}\right)($ Fig. $4 \mathrm{e})$. The lattice strain does not depend significantly on $\psi$, but it does vary with $h k l$. The variation among the various $\varepsilon_{\psi}^{h k l_{\gamma}}$ increases during continuous cooling and, analogously, is most pronounced at $298 \mathrm{~K}\left(25^{\circ} \mathrm{C}\right)(\mathrm{Fig}$. 4e). Stress analysis reveals that compressive stress of type II builds up in austenite for $f^{\alpha^{\prime}}>0.2$ (Fig. 6a). Compressive stress increases steadily with a reduction of the austenite fraction and depends on the $\varepsilon_{\psi}^{h k l_{\gamma}}$ from which it is evaluated.
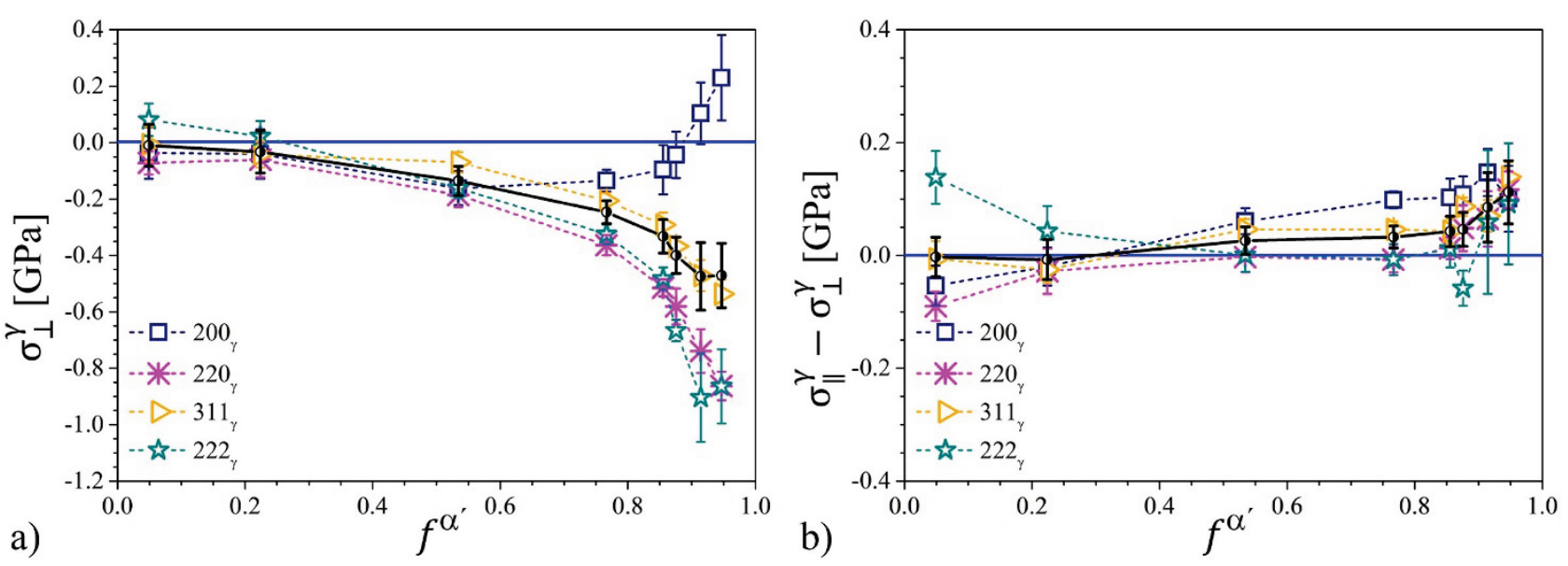

Figure 6. State of stress in austenite evaluated from lattice strains obtained for $200_{\gamma}, 220_{\gamma}, 311_{\gamma}$ and $222_{\gamma}$ and plotted versus the fraction of martensite formed $f^{\alpha^{\prime}}$ : a) stress component in the direction perpendicular to the sample surface $\sigma_{\perp}^{\gamma}$; b) difference between the stress components parallel and perpendicular to the sample surface $\sigma_{\|}^{\gamma}-\sigma_{\perp}^{\gamma}$. The black lines and symbols represent the state of stress averaged over all probed reflections. Error bars indicate the standard error of the estimate for linear regression of data in Fig. 2. An additional experimental error related to the alignment of the diffractometer is estimated in the order of $\pm 30 \mathrm{MPa}$. 

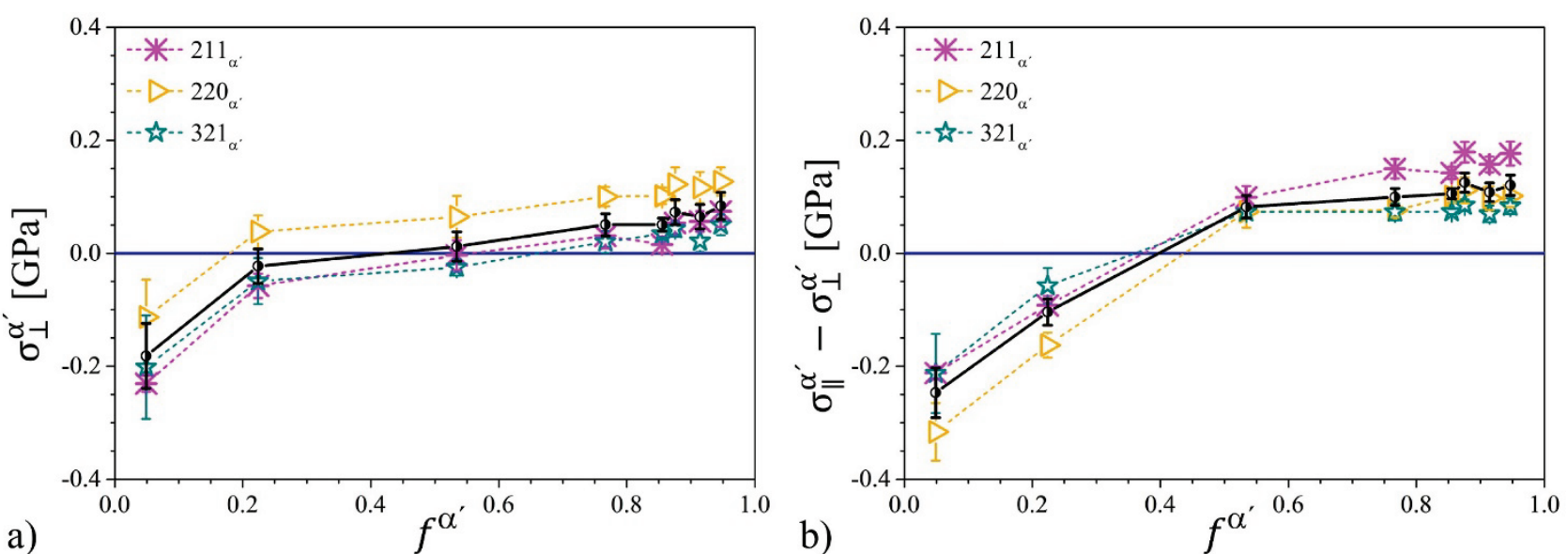

After quenching, $\sigma_{\perp}^{\gamma}$ equals $+0.23 \mathrm{GPa},-0.86 \mathrm{GPa},-0.54 \mathrm{GPa}$ and $-0.86 \mathrm{GPa}$ when evaluated from $200_{\gamma}, 220_{\gamma}, 311_{\gamma}$ and $222_{\gamma}$, respectively, and $\left\langle\sigma_{\perp}^{\gamma}\right\rangle=-0.51 \mathrm{GPa}$. The atypical behaviour of $200_{\gamma}$ cannot be explained solely in terms of elastic anisotropy in austenite (see previous paragraph). This behavior is consistent with observations in the literature on the influence of plastic accommodation of the volume changes on the suitability of $h k l$ for the determination of residual stresses in f.c.c. metals [29-32] and strongly suggests that plastic deformation has occurred in austenite during martensite formation.

During the transformation, the state of stress in (untransformed) austenite is close to hydrostatic within the probed volume (i.e. $\sigma_{\|}^{\gamma}-\sigma_{\perp}^{\gamma} \ll \sigma_{\perp}^{\gamma}$ ). However, measurable macro-stress is present, as reflected by $\sigma_{\|}^{\gamma} \neq \sigma_{\perp}^{\gamma}$ (Fig. 6b). At the beginning of the transformation, $\sigma_{\|}^{\gamma}>\sigma_{\perp}^{\gamma}$ as evaluated from $\varepsilon_{\psi}^{222 \gamma}$, which, among the probed $\gamma$ reflections, offers the largest information depth. Probing the other $h k l$ at shallower information depths it is found that $\sigma_{\|}^{\gamma} \leq \sigma_{\perp}^{\gamma}$. Along with an increase of the fraction of martensite, a small tensile macro-stresses, i.e. $\left(\sigma_{\|}^{\gamma}>\sigma_{\perp}^{\gamma}\right)$, builds up for $f^{\alpha^{\prime}}>0.2$.

Fig. 5 shows that $a_{\psi}^{\alpha^{\prime}}$ was linearly dependent on $\sin ^{2} \psi$ at $T=403 K\left(130{ }^{\circ} \mathrm{C}\right)$, i.e. just below $M_{S}$ (Fig. 5b). The slope of $a_{\psi}^{\alpha^{\prime}}$ versus $\sin ^{2} \psi$ is negative. Upon cooling to $\mathrm{T}=373 \mathrm{~K}\left(100^{\circ} \mathrm{C}\right)$, the slope of $a_{\psi}^{\alpha^{\prime}}$ versus $\sin ^{2} \psi$ reverts to positive (Fig. 5c) and a non-linear dependence of $a_{\psi}^{\alpha^{\prime}}$ on $\sin ^{2} \psi$ is observed for $200_{\alpha^{\prime}}$, reflecting the oscillations in the $a_{\psi}^{\alpha^{\prime}}$ vs. $\sin ^{2} \psi$ distribution in the "as normalized" condition (Fig. 5a). On continuous cooling to $298 \mathrm{~K}\left(25^{\circ} \mathrm{C}\right), a_{\psi}^{\alpha^{\prime}}$ shrinks at a rate 
commensurate with the thermal expansion coefficient $\lambda_{\alpha^{\prime}}$ and $\varepsilon_{\psi}^{h k l_{\alpha^{\prime}}}$ does not vary significantly with $h k l$ (Figs. 5c-e).

Stress evaluation reveals that martensite experiences an average compressive stress at the beginning of the transformation, which reverts into an average tensile stress for $f^{\alpha^{\prime}}>0.5$ (Fig. 7a). The state of stress is not particularly sensitive to the $h k l$ used for probing the lattice strain. Finally, after quenching, $\left\langle\sigma_{\perp}^{\alpha^{\prime}}\right\rangle=+0.08 G P a$.

Fig. $7 \mathrm{~b}$ also indicates the presence of macro-stresses. At the beginning of the process, macrostresses are compressive and significant, approx. $-0.25 \mathrm{GPa}$. With increasing martensite content, compression decreases and is reversed into tensile macro-stress for $f^{\alpha^{\prime}}>0.2$.

\subsubsection{The tempered condition}

The values of $a_{\psi}^{h k l_{\gamma}}$ and $a_{\psi}^{h k l_{\alpha^{\prime}}}$ are shown as a function of $\sin ^{2} \psi$ in Figs. $4 \mathrm{f}$ and $5 \mathrm{f}$, respectively. The fraction of martensite in the sample is $f^{\alpha^{\prime}}=0.95$, consistent with the "as normalized" and "as quenched" conditions. The result in Fig. $4 \mathrm{f}$ shows that $a_{\psi}^{h k l_{\gamma}}$ varies with $h k l$, but not with $\psi$. Comparison of $a^{\gamma}$ with $a_{r e f}^{\gamma}$ reveals that lattice strain evaluated from $200_{\gamma}$ and $311_{\gamma}$ is negligibly small, whereas $\varepsilon^{222} \gamma \ll 0$. Stress analysis shows that $\sigma_{\perp}^{\gamma}$ is $-0.07 \mathrm{GPa},-0.23 \mathrm{GPa},-0.08 \mathrm{GPa}$ and $-0.86 \mathrm{GPa}$ when evaluated based on $200_{\gamma}, 220_{\gamma}, 311_{\gamma}$ and $222_{\gamma}$, respectively. The stress is approximately hydrostatic within the probed volume, with $\left\langle\sigma_{\perp}^{\gamma}\right\rangle=-0.31 \mathrm{GPa}$ and $\sigma_{\|}^{\gamma}-\sigma_{\perp}^{\gamma}=$ $+0.04 \mathrm{GPa}$. The $h k l$-dependent lattice strain suggests that a hydrostatic state of stress does not apply at the length scale of a single austenite grain.

Fig. 5f shows that $a_{\psi}^{h k l_{\alpha^{\prime}}}$ evaluated from $211_{\alpha^{\prime}}, 220_{\alpha^{\prime}}$ and $321_{\alpha^{\prime}}$ is a linear function of $\sin ^{2} \psi$ but does not vary with $h k l ; a_{\psi}^{200_{\alpha^{\prime}}}$, instead, shows a $\sin ^{2} \psi$ dependence characterized by oscillations as earlier reported for the material in "as normalized" and "as quenched" conditions. Stress analysis was based on $211_{\alpha^{\prime}}, 220_{\alpha^{\prime}}$ and $321_{\alpha^{\prime}}$.Under the assumption that the chemical composition of the martensite has not changed during tempering it is obtained $\left\langle\sigma_{\perp}^{\alpha^{\prime}}\right\rangle=-0.09 \mathrm{GPa}$ and $\sigma_{\|}^{\alpha^{\prime}}-\sigma_{\perp}^{\alpha^{\prime}}=$ $+0.08 \mathrm{GPa}$.

Nevertheless, the material is almost fully martensitic during tempering. A significant variation of $\left\langle\sigma_{\perp}^{\alpha^{\prime}}\right\rangle$ from $\left\langle\sigma_{\perp}^{\alpha^{\prime}}\right\rangle=0.08 \mathrm{GPa}$ before to tempering to $\left\langle\sigma_{\perp}^{\alpha^{\prime}}\right\rangle=-0.09 \mathrm{GPa}$ after tempering would imply an enormous (about $3 \mathrm{GPa}$ ) balancing variation in $\left\langle\sigma_{\perp}^{\gamma}\right\rangle$, (cf. Eq.7), which is not confirmed by the experimental data. Evidently, the shrinkage of the martensite lattice from the "as quenched" to the "tempered" condition is not due to a change of $\left\langle\sigma_{\perp}^{\alpha^{\prime}}\right\rangle$, but has its origin in a change in chemical 
composition. The measured change in the lattice parameter corresponds to expelling approx. 0.03 $\mathrm{wt} \% \mathrm{C}+\mathrm{N}$ from solid solution in martensite during tempering to $748 \mathrm{~K}\left(475^{\circ} \mathrm{C}\right)$.

\section{Discussion}

\subsection{Partitioning of stresses in austenite and martensite during martensite formation}

Historically, the evolution of the phase specific stresses, $\left\langle\sigma^{\varphi}\right\rangle$, in austenite and martensite during the austenite-to-martensite transformation has been investigated by measuring the evolution of the phase specific strain, $\varepsilon^{\varphi}$, as a function of the corresponding phase fraction, $f^{\varphi}$, either in a single direction $[14,16-18,22,23]$, or in a set of directions (approx.) normal to the incident beam [19,20,27]. These investigations departed from the hypothesis that macro-stresses are negligible within the volume probed by XRD.
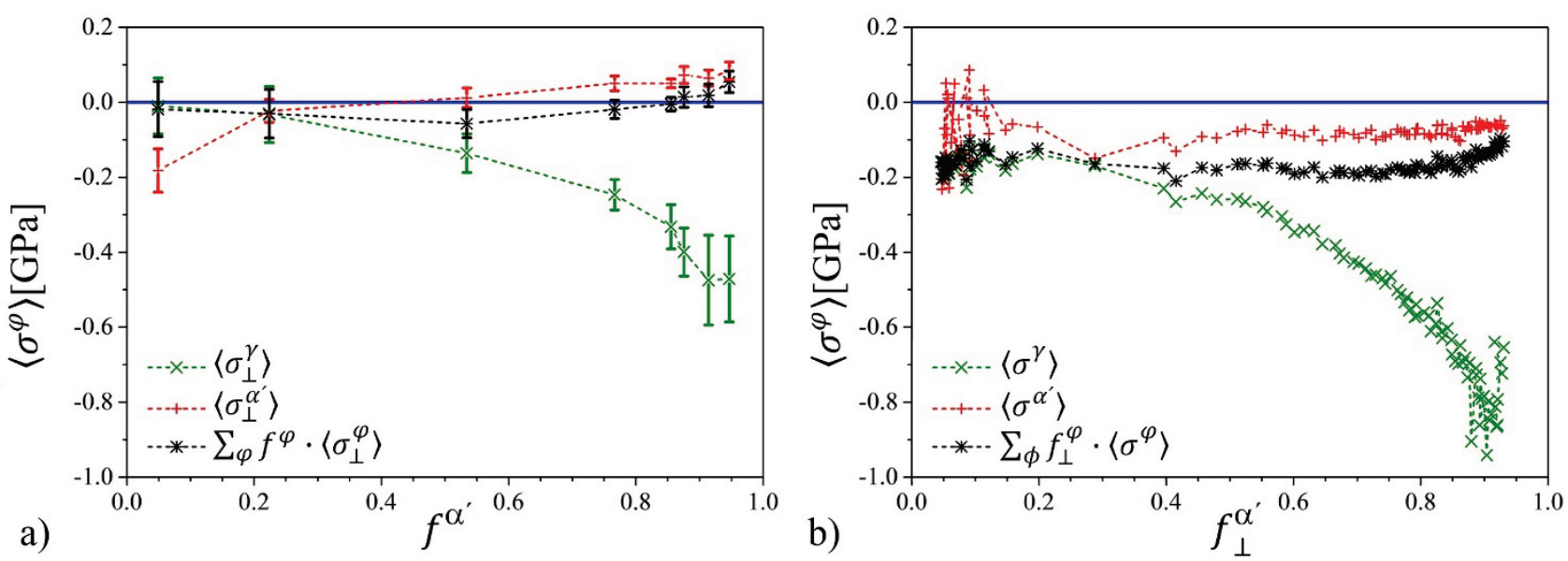

Figure 8. Calculated phase-specific stresses $\left\langle\sigma^{\varphi}\right\rangle$ for a) sample 1 and b) sample 2. Data re plotted versus fraction transformed $f^{\alpha^{\prime}}$ (averaged over all $\psi$ ) and fraction transformed evaluated in the direction normal to the sample surface $f_{\perp}^{\alpha^{\prime}}$, for sample 1 and sample 2, respectively. Error bars indicates minimum and maximum values based on data in Figs. 6a and 7a. An additional experimental error related to the alignment of the diffractometer is estimated in the order of \pm 30 MPa. Error analysis do not consider uncertainty in the determination of $f^{\alpha^{\prime}}$ and $f_{\perp}^{\alpha^{\prime}}$.

In the present work, the evolution of stress in the material during martensite formation including the separation of macro- and micro-stresses was investigated in situ for the first time (sample 1). To verify whether the measured lattice strains in austenite can be ascribed to (micro-)stresses of type II, a balancing of average stress values in the phases in the sample (cf. Eq. 7) with $f^{\alpha^{\prime}}$ was considered. The results of this verification for the stress values presented in Fig. 6a and 7a are shown in Fig. 8a. Fig. 8a shows that, within experimental accuracy, internal balance of average stresses is satisfied from the onset of the transformation to its completion. At the beginning of the transformation martensite is the minority phase and experiences significant phase specific compressive (micro- 
)stress of type II, which is balanced by very small tensile (micro-)stress of type II in the dominating austenite. During martensite formation, the state of stress in the phases reverses. For $f^{\alpha}>0.2$, tension builds up in martensite and compression develops in austenite. At the end of the transformation, significant compressive (micro-)stress of type II in austenite is balanced by small tensile (micro-)stress of type II in martensite. Data does not provide a reason for the observed reversion of the state of stress in the phases during transformation.

The importance of performing in situ stress analysis to evaluate the state of stress in the phases is clarified from comparing Fig. 8a and Fig. 8b. The stress values presented in Fig. 8b (sample 2) were obtained applying Eq. 2, under the assumption that the state of stress in both phases is hydrostatic. Fig. $8 \mathrm{~b}$ indicates that martensite formation leads to compressive stresses in both martensite and austenite, in agreement with a previous claim in Ref. [14]. The in situ stress analysis as determined for sample 1 demonstrates that this conclusion is incorrect. Evidently, Eq. 2 can be applied only if the assumption that macro-stresses are negligible is validated.

Macro-stresses can be introduced as a consequence of a variation in the degree of transformation over the sample thickness. It is well accepted that martensite formation starts at the surface and is associated with a volume expansion. This expansion is partially relaxed in the $\perp$ direction and partially accommodated within the sample. Martensite, which is concentrated at the sample surface, experiences compressive macro-stresses (Fig. 7b, left), which are balanced by tensile macro-stresses in the bulk austenite, as reflected in Fig. $6 \mathrm{~b}$ (left) by probing the $222_{\gamma}$ reflection. Thereafter, continuous cooling promotes continuation of the transformation (from left to right in Figs. 6 and 7), including transformation of the bulk. Transformation of the bulk, is similarly associated with a volume expansion. However, the expansion of the bulk is fully counteracted by the martensitic case, which surrounds it. As a result, macro-stress in the near surface region changes from compressive to tensile during continued transformation, as evidenced in Figs. 6 and 7 at $f^{\alpha^{\prime}}>0.2$.

Additionally, $h k l$ dependent lattice strain in austenite should be addressed. Historically, the lattice strain in austenite, $\varepsilon^{\gamma}$, developing during martensite formation was obtained from either $a^{\gamma}$ evaluated from the position of a single reflection [11-15,23,24], or from an average $a^{\gamma}$ value obtained from the simultaneous evaluation of the position of all probed reflections [19,20,27]. In a few studies [16,17,22], $h k l$-specific $\varepsilon^{h k l_{\gamma}}$ relying on an independent evaluation of corresponding $a^{h k l_{\gamma}}$ were presented. These latter studies revealed that the lattice strain is compressive $\left(\varepsilon^{h k l_{\gamma}}<0\right)$ and largest for $111_{\gamma} / 222_{\gamma}[16,17,22]$, moderately negative and close to the average value for $311_{\gamma}$ $[16,17]$ and negligible $[16,17]$ or positive, for $200_{\gamma}$ [22]. These observations are confirmed by the results obtained in the present investigation. The $h k l$-dependence of lattice strain in austenite can 
535 partly be explained from the anisotropic elastic properties of austenite (see section 3.3.). However, 536 lattice strains of opposite sign for different $h k l$, as observed for the material as quenched and as 537 tempered, cannot be reconciled with elastic anisotropy only. Plastic accommodation of the 538 transformation strain is considered responsible for this behavior. When a unit of martensite forms, 539 the transformation evokes tension in the surrounding austenite, which yields heterogeneously.

540 Crystal plasticity in f.c.c. crystals yields $h k l$ dependent non-linear stress-strain behaviour in addition 541 to elastic anisotropy and consequently, a change of the apparent elastic constants. As a result, 542 anisotropic residual stress remains after unloading. Unloading of the state of tension in austenite 543 takes place during continued martensite formation, as revealed by the development of an average 544 compressive state of stress in this phase.

545 Unfortunately, controversy exists as to which $h k l$ s should be chosen to prevent these anisotropy 546 effects (cf. Ref. [29-31] vs. Ref. [32]). If only elastic anisotropy is responsible for $h k l$ dependence, 547 averaging is effectively obtained by choosing the $311_{\gamma}$ reflection, as the corresponding orientation 548 parameter $3 \Gamma$ for this reflection is close to 0.5 , i.e. half way the range from 0 to 1 . In the present 549 work, $\left\langle\sigma^{\gamma}\right\rangle$ was taken as the average value for stress obtained from lattice strain over $\varepsilon^{200_{\gamma}}, \varepsilon^{220_{\gamma}}$, $550 \varepsilon^{311_{\gamma}}$ and $\varepsilon^{222_{\gamma}}$. This procedure yielded the conclusion that Eq. 3 was satisfied throughout the 551 whole transformation process. It is explicitly mentioned that choosing the $311_{\gamma}$ reflection would 552 have given a comparable result.

553 Further insight in the elasto-plastic interaction between the phases during transformation is provided 554 by data collected for the $\psi$-dependent lattice parameter $a_{\psi}^{200_{\alpha^{\prime}}}$. A rigorous treatment to interpret a $d$ 555 vs. $\sin ^{2} \psi$ distribution characterized by oscillations is missing [4]. However, in a cubic phase, 556 oscillations in the d-vs. $\sin ^{2} \psi$ distribution can be caused by texture and/or plastic strain. In textured 557 elastically strained cubic materials, no oscillation of $a_{\psi}^{\alpha^{\prime}}$ versus $\sin ^{2} \psi$ is expected for the $h 00_{\alpha^{\prime}}$ 558 reflections [4,54]. On the other hand, oscillations will arise in plastically strained crystals, and will 559 be most significant for $200_{\alpha^{\prime}}[4,55]$. Hence, the present data indicates that both austenite and 560 martensite are plastically strained during the transformation.

561 Finally, we suggest that a consistent description of the evolution of strain and phase-specific 562 stresses in the material during the austenite-to-martensite transformation requires that the elasto563 plastic interaction of the two phases and the elasto-plastic anisotropy of the two crystal lattices is 564 taken into account. Developing such description is beyond the scope of the present work. 
566 Stress analysis was applied to investigate in situ stresses of type II evoked by the austenite-to-

567 martensite transformation in steel. The analysis shows indeed that such stresses do build up.

568 Stresses of type II have a significant magnitude for the minority phases, i.e. for martensite at the 569 beginning of the transformation and for austenite at the end.

570 Stresses of type II in the minority phase are compressive and are balanced by small tensile stresses 571 of type II in the majority phase.

572 Strain in austenite is anisotropic: maximum compression is observed for spacings of the (222) $\gamma$ and $573(220)_{\gamma}$ planes, while tension was revealed in the $[200]_{\gamma}$ direction. Anisotropic strain in austenite is 574 particularly significant in the latest stage of the transformation.

575 Strain anisotropy in austenite and a d-vs. $\sin ^{2} \psi$ distribution characterized by oscillations in 576 martensite indicate that both phases are subjected to plastic deformation during quenching.

577 An in-depth evaluation of the state of stress in the phases requires further investigation in the effect 578 of plasticity on the determination of stresses in iron-based alloys.

579 Tempering of soft martensitic stainless steel to $748 \mathrm{~K}\left(475^{\circ} \mathrm{C}\right)$ yields partial relaxation of stresses.

580 Acknowledgements

581 M. Klaus, D. Apel and Ch. Genzel from Helmholtz Zentrum für Materialien und Energie (HZME) 582 are acknowledged for their enthusiastic support during the activity at the HZB-BESSY II 583 synchrotron facility and during subsequent data analysis. The activity was supported by the 584 European Commission under the $7^{\text {th }}$ Framework Program through the 'Research Infrastructure' 585 action of the 'Capacities' Programme, CALIPSO (Grant n: 312284) and by the Danish Natural 586 Science Research Council via Danscatt. The Danish Council for Independent Research (G.R. grant: 587 DFF-4005-00223) and the Danish Underground Consortium are gratefully acknowledged for 588 financial support.

\section{References}

590 [1] P. J. Withers, W.M. Stobbs, O.B. Pedersen: Acta metal., 1989, vol. 37, pp. 3061-3084

591 [2] O.B. Pedersen: Acta Metall., 1983, vol. 31, pp. 1795-1808

592 [3] P.J. Withers and H.K.D.H. Bhadeshia: Mater. Sci. Tech., 2001, vol. 17, pp. 366-375

593 [4] V. Hauk: Structural and Residual Stress Analysis by Non-Destructive Methods: Evaluation594 Application - Assessment, Elsevier Science, 1997 
595 [5] P.J. Withers and H.K.D.H. Bhadeshia: Mater. Sci. Tech., 2001, vol. 17, pp. 355-365

596 [6] G.B. Olson and W.S. Owen: Martensite, ASM International, (OH) USA, 1992

597 [7] Z. Nishiyama, Martensitic Transformation, Academic Press, New York, USA, 1978

598 [8] J.W. Christian: Proc. Int. Conf. on martensitic Transformation, 1979, pp. 220-233

599 [9] H.K.D.H. Bhadeshia: Mater. Sci. Eng. A, 2004, vol. 378, pp. 34-39

600 [10] G.E. Totten, M. Howes, T. Inoue: Handbook of Residual Stress and Deformation of Steel, 601 ASM International, (OH) USA, 2002

602 [11] V.I. Gridnev, V.I. Trefilov: Dokl. Akad. Nauk SSSR, 1957, vol. 116, pp. 60-62

603 [12] N. Ridley, H. Stuart, L. Zwell: Trans. AIME, 1969, vol. 245, pp. 1834-1836

604 [13] K. Ya Golovchiner: Fiz. Metal. Metalloved., 1974, vol. 37, pp. 363-368

605 [14] Y. Tanaka and K. Shimizu: Trans. JIM, 1980, vol. 21, pp. 42-50

606 [15] L. Cheng, A. Bottger, T.H. de Keijser, E.J. Mittemeijer: Scripta Mater., 1990, vol. 24, pp. 509$607 \quad 514$

608 [16] M. Villa, F.B. Grumsen, K. Pantleon, M.A.J. Somers: Scripta Mater., 2012, vol. 67, pp. 621$609 \quad 624$

610 [17] M. Villa, K. Pantleon, M.A.J. Somers: J. Alloys Compd., 2013, vol. 577, pp. S543-S548

611 [18] M. Villa, K. Pantleon, M.A.J. Somers: Acta mater., 2014, vol. 65, pp. 383-392

612 [19] J. Epp.: Advanced Mater. Res., 2014, vol. 996, pp. 525-531

613 [20] J. Epp.: Proc. IFHTSE 2016, 2016, pp. 440-447

614 [21] N. Nakada, Y. Ishibashi, T. Tsuchiyama, S. Takaki: Acta Mater., 2016, vol. 110, pp. 95-112

615 [22] V.M. Yeshov, M.L. Oslon: Fiz. Metal. Metalloved., 1968, vol. 25, pp. 874-881

616 [23] V.M. Yeshov, M.L. Oslon: Fiz. Metal. Metalloved., 1972, vol. 33, pp. 215-217

617 [24] E. Scheil, E. Saftig. Arch. Eisenhuttenw. 1957, vol. 28, pp. 49-51

618 [25] K. Ullakko and V.G. Gavriljuk: Acta Metall. Mater., 1992, vol. 40, pp. 2471-2482

619 [26] K. Ullakko: Aging of iron-based martensites at low-temperatures, PhD thesis, Helsinki, 1992

620 [27] D. San Martin, E. Jimenez-Melero, J.A. Duffy, V. Honkimaki, S. van der Zwaag, N.H. van 621 Dijk: J. Appl. Crystallogr., 2012, vol.45, pp. 748-757

622 [28] T. Kakeshita, T. Saburi, K. Kind, S. Endo: Phase Transitions, 1999, vol. 70, pp. 65-113. 
623 [29] A.N. Ezeilo, G.A. Webster, P.J. Webster, X. Wang: Physica B, 1992, vol. 180-181, pp. 1044$624 \quad 1046$

625 [30] B. Clausen, T. Lorentzen, T. Leffers: Acta. Mater., 1998, vol. 46, pp. 3087-3098

626 [31] E.C. Oliver: The generation of internal stresses in single and two phase materials, PhD Thesis, 627 Manchester, 2002

628 [32] B. Clausen, T. Leffers, T. Lorentzen: Acta. Mater.,, 2003, vol. 51, pp. 6181-6188

629 [33] F. Niessen, M. Villa, D. Apel, O. Keßler, M. Reich, J. Hald, M.A.J. Somers: Mater. Sci. 630 Forum, 2016, vol. 879, pp. 1381-1386

631 [34] F. Niessen, M. Villa, J. Hald, M. AJ Somers: Mater. and Design, 2017, vol. 116, pp. 8-15.

632 [35] Ch. Genzel, I. A. Denks, M. Klaus, Mater. Sci. Forum, 2006, vol. 524-525, pp. 193-198

633 [36] B.C. Giessen, G.E. Gordon: Science, 1968, vol. 159, pp. 973-975

634 [37] Ch. Genzel, I.A. Denks, M. Klaus: Residual Stress Analysis by X-Ray Diffraction Methods, in 635 Modern Diffraction Methods, Wiley-VCH, 2013, pp. 127-154

636 [38] E.S.U. Laine: J. Phys. F Met. Phys., 1978, vol. 8, pp. 1343-1348

637 [39] Landoldt-Börnstein, New Series, Group III Vol. 11, Springer, Berlin 1979

638 [40] H. Behnken: Berechnung und Ermittlung der röntgenographischen Elastizitätskonstanten 639 sowie der Mikro- und Makro-Spannungen heterogener und texturierter Werkstoffe, $\mathrm{PhD}$ thesis, 640 RWTH Aachen, 1992

641 [41] E. Kröner: Z. Physik, 1958, vol. 151, pp. 504-518

642 [42] J.D. Eshelby: Proc. Roy. Soc. London A, 1957, vol. 241, pp. 376-396

643 [43] A. Teklu, H. Ledbetter, S. Kim, L.A. Boatner, M. McGuire, V. Keppens: Metall. Mater. Trans. 644 A, 2004, vol. 35, pp. 3149-3154

645 [44] H.M. Ledbetter and M.W. Austin: Mater Sci Eng, 1985, vol. 70, pp. 143-149

646 [45] Y.S. Touloukian, Thermophysical Properties of Matter. The TPRC Data Series 12: Thermal 647 Expansion Metallic Elements and alloys, IFI/Plenum, 1975

648 [46] T. Gnaupel-Herold, A. Creuziger: Mater. Sci. Eng. A, 2011, vol. 528, pp. 3594-3600

649 [47] A. Bojack, L. Zhao, P.F. Morris, J. Sietsma: Mater. Charact, 2012, vol. 7, pp. 77-86

650 [48] C.M. Wayman: Iron and Steel Inst. - Special Report, 1965, pp. 153-163

651 [49] J. Pak, D.W. Suh, H.K.D.H. Bhadeshia: Metall. Mater. Trans. A, 2012, vol. 43, pp. 4520-4524 
652 [50] J.A. Klostermann and W.G. Burgers: Acta Metall., 1964, vol. 12, pp. 355-360

653 [51] J.A. Klostermann: J. Less-Common Metals, 1972, vol. 28, pp. 75-94

654 [52] G. Faria, J. Escobar, A.J. Ramirez: Proc. Int. Conf. on Solid-solid Phase Transf. in Inorganic 655 Mater. 2015, 2015, pp. 637-638

656 [53] A. Beneteau, E. Aeby-Gautier, G. Geandier, P. Weisbecker, A. Redjaimia, B. Appolaire: Acta 657 Mater., 2014, vol. 81, pp. 30-40

658 [54] A.J.C. Wilson: Acta Cryst., 1952, vol. 5, pp. 318-322

659 [55] J.W.L. Pang, T.M. Holden, T.E. Mason: J. Strain Analysis Eng. Design, 1998, vol. 33, pp. $373-$ $660 \quad 383$ 